\title{
A Proposed Theoretical Model for Mobile Commerce Acceptance
}

\author{
Hongen Ji \\ School of Management Engineering \\ Zhengzhou University \\ Zhengzhou, P.R. China \\ jihongen@gmail.com
}

\begin{abstract}
-as the intelligent mobile device terminals, such as smartphone and tablet, more and more pervasive and affordable, mobile commerce has become the hottest issue around the world. User acceptance is one of the key fundamentals for development and success of mobile commerce. Build on the Unified Theory of Acceptance and Use of mobile commerce and its recent extension for mobile commerce, we proposed a study design and a theoretical research model to investigate acceptance of mobile commerce by users. As technology adoption research is still dominated by quantitative methods, the study in this paper combines qualitative and quantitative phase.
\end{abstract}

Keywords-mobile commerce; mobile commerce acceptance; ecommerce; use behavior

\section{INTRODUCTION}

As smartphone and other mobile device become pervasive and affordable as well as mobile internet ubiquitous, mobile commerce has taken off [1]. Narrowly defined, mobile commerce (m-commerce) refers to various monetary transactions via mobile networks. Broadly defined, mobile commerce refers to any applications and services supported by mobile networks and mobile devices [2].

Industries of varieties have begun to realize that the target audiences for their business applications have shifted massive numbers from the use of traditional personal computers such as desktops and laptops, to using mobile devices such as smartphones and tablets for accessing the internet and for obtaining the information they seek [3]. Although China ranks first in terms of the number of mobile phone users, and the number of mobile phone netizens has achieved 303 million in the end of 2010[4]. The number of mobile commerce consumers is relatively small compared with other countries and region, i.e., Japan and Korea [2].

Compared with the traditional desktop based e-commerce, the mobile commerce has offered many advantages, such as anytime, anywhere, instant connectivity, more personalization, more location aware, and more context-aware. Mobile commerce has its own technological infrastructure, new business models, new value chain and new value for consumers. The research of consumers' acceptance mobile commerce requires new perspectives and new theoretical framework [2]. The purpose of this paper presents a study design and a theoretical model to investigate acceptance of mobile commerce.

\section{RELATED RESEARCH THEORY}

Technology adoption is one of most mature streams in information systems research. In current studies, the research theories can be divided into four categories: TTF (TaskTechnology Fit), CPV (Customer Perceived Value), IDT (Innovation Diffusion Theory) and TRA (Theory of Reasoned Action) and its family theories including TAM (Technology Acceptance Model), TPB (the Theory of Planned Behavior) and UTAUT (Unified Theory of Acceptance and Use of Technology) [5]. In this paper research, we build on studies exploring acceptance of mobile commerce based on UTAUT. The UTAUT model is shown in Fig.1.

UTAUT was proposed by Venkatesh et al in 2003[6]. The UTAUT model was developed through the comparison and merging of eight well known models: TRA, TAM, TPB, a combination of TAM and TPB, the model of PC Utilization (MPCU), IDT, and Social Cognitive theory (SCT) [7]. Although the eight models of acceptance have been used to predict the acceptance and use of technology in an organization, they typically have explain less than 50 percent of variance in use intention to utilize a new technology[6]. The UTAUT model explains approximately 70 percent of variance and will be used as the basis for the model of mobile commerce acceptance [7].

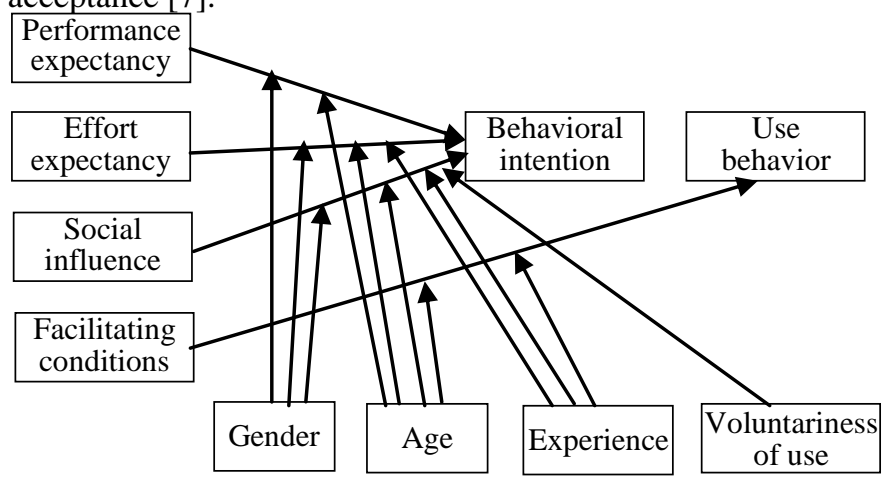

Figure 1. UTAUT model

Combing other eight models, the four determinants of behavior intention were derived. The first determinant, performance expectancy defines the degree that one believes using the technology will yield certain rewards. The second determinant, effort expectancy reflects the ease of use of technology. The third determinant, social influence relates how influential others view the importance of using the systems. 
The fourth determinant, facilitating conditions is the level of supporting technology an infrastructure in the organization. Four moderating variables were identified for UTAUT model: age, gender, experience, and voluntariness of use.

\section{METHOD}

Current studies on consumer adoption are mainly based on TRA and its family theories. As mobile commerce is a relatively new research area, researchers should try to expand their research methods, qualitative methods such as focus groups and depth interviews are also helpful [5]. Focus group interviews have been suggested as a suitable method for explorative studies, and previous research has demonstrated their feasibility in studying innovative mobile services [8]. In this paper, the proposed study consists four phases, combing qualitative and quantitative research methods. Tab.1 outlines the study phases with their research methods.

TABLE I. STUDY PHASES AND RESEARCH METHODS

\begin{tabular}{ll}
\hline \multicolumn{1}{c}{ Study phase } & \multicolumn{1}{c}{ Research method } \\
\hline $\begin{array}{l}\text { Phase1: review the literature on } \\
\text { mobile commerce and consumer } \\
\text { adoption; and developing a } \\
\text { theory-based model }\end{array}$ & Systematic literature review \\
\hline $\begin{array}{l}\text { Phase2: gain the background } \\
\text { information for the phase3 }\end{array}$ & Questionnaire survey \\
\hline $\begin{array}{l}\text { Phase3: interviewing the } \\
\text { consumer on their adoption and }\end{array}$ & Focus group interviews \\
use of mobile commerce & \\
\hline $\begin{array}{l}\text { Phase4: understanding acceptance } \\
\text { and use of mobile commerce via } \\
\text { large scale sample }\end{array}$ & Empirical survey study \\
\hline
\end{tabular}

Phase1 has been concluded in this paper, and a theorybased model has proposed.

\section{THEORETICAL MODEL DEVELOPMENT}

\section{A. Trust and Privacy}

The UTAUT model was designed to address technology acceptance by individuals who jobs involve using the technology, but doesn't address the relationship between the external customer and business [7]. The mobile commerce acceptance model proposed in this paper includes both technology component and relationship component, referred to here as trust and privacy.

Consumer trust is recognized as one of most important factors in the study of both e-commerce and marketing [2]. Siau and shen classified trust into two categories: trust of technology and trust of mobile service providers. Because mobile internet and commerce is still in its early development stage, technology and policy is not perfect. Therefore, trust is especially important for user acceptance. Dayal et al. believe that if there is lack of trust between the consumer and service providers, the user will be unable to establish a long-term relationship [10]. The research of Gefen concluded that trust was an essential component for developing loyalty between user and on-line business [11]. Niina' finding indicated that trust in mobile service providers and merchants reduced perceived risks of mobile commerce [13]. Business trustworthiness was also shown to be a determinant in user acceptance of e-commerce [12].
The information collected by an organization may be viewed by its management as property of that organization. So the information treated as any other resource. The use of the internet for commerce has greatly enhanced the capability of businesses to collect personal information. Now, technological advance available through mobile commerce also facilitate the capture of the user's information such as physical location [7]. However, customers believe they have the right to control the use of their personal information [13].

Context-aware and location-based applications and services provide a great commercial potential in mobile commerce. It also poses potential privacy problems since the service providers will know the exact location of the user and might even know the user's travel pattern [2]. As a result, consumers are concerning with their privacy protection [7]. Sheng et al. believe that privacy is a key factor in the adoption of mobile commerce by consumers [14]. Spiekermann et al. point out that privacy concerns are one factor of online behavior [15].

There is close relationship between privacy protection and trust. However, Min Qingfei et al considered that privacy protection is different from trust, because perception of privacy protection is also affected by the third party, such as government and its privacy protection policy [16].

\section{B. Performance Expectancy}

Venkatesh described that perception of increased performance from a new technology is affected by user's previous experience, skill level, enjoyment and overall usability of the technology [17]. Most mobile commerce users are likely to have had experience shopping on-line using a PC, so would likely to have similar expectations concerning their use of mobile commerce. As smartphone has become pervasive an affordable in China, the frequency of smartphone users accessing internet was significantly higher than overall mobile phone netizens [4]. This indicates that more and more mobile phone netizens have had experience with mobile commerce.

According DISTIMO survey of app download volumes in AppStore, games, entertainment and social networking are the top three applications in smartphone. As different usage of IS leads different adoption behavioral factors [18], perceived enjoyment or playfulness is more important than perceived usefulness for most mobile commerce users. So the theoretical UTAUT model must concern playfulness, satisfaction, leisure, quality of life and so on.

\section{Effort Expectancy}

Venkatesh et al considered that the effort necessary to learn and use a new technology affects its acceptance and use [6]. Mobile terminals, such as smartphone and table t, have small screen interfaces, non-keyboard user input mechanism, and sites with multi-layered web pages can be discouraging, particularly to new users [19][20]. Service providers need for more attention to usability and user interaction design for mobile commerce users. Identifying non-keyboard ways in which information can be gathered and delivered to mobile applications is a significant challenge. Additional, end users of a mobile device are typically holding the device in their hand while also interacting with the surrounding reality of their physical situation. These application users typically cannot concentrate intently on the mobile application for very long before they need to switch their attention to their physical 
surroundings. The interaction model for users of mobile applications is short, interrupted, and "bursty," meaning that they need to very quickly complete the application task before switching attention [3].

So the new interfaces, possibly involving speech recognition and control combined highly personalized web sites could enhance user acceptance mobile commerce [21][22].

\section{Social Influence}

Relatives, friends, co-workers, and other considered important to an individual often influence individual behavior and contribute to user acceptance of new IT [6][7].

Several scholars consider the network externality as a success factor of mobile commerce [23]. Ruebeck et al. consider network externalities as special kinds of externalities in which one person's utility depends on the number of other people in that person's network [24], so the number of other people who choose the same mobile applications .

\section{E. Facilitating Conditions}

When mobile services providers offer help through their sites, facilitate easy navigation, address frequently asked questions, and create other facilities for making site and applications usage easier, they encourage users, particular new users, to participate [7]. Several researchers consider that accessibility, immediacy, mobility, and positioning ability are the main differences between e-commerce and mobile commerce [23]. These factors may help users easily access the internet, make convenient transactions, and reduce their investments of time or effort [25][26].

Min Qingfei et al discussed the cost of mobile commerce. They consider that cost associated with wireless transaction is still relatively high and many wireless users have to bear the cost themselves. It will directly affect the users' adoption behavior, and should be included in UTAUT's facilitating conditions [16]. Anindya G. et al discuss the search costs, and consider that primacy effect-related search costs are higher in mobile phone and the cost of acquiring timely information appears to be lower on a mobile phone than on a PC [27].

\section{F. Other Moderating Factors}

First, voluntariness of use is insignificant for individualized systems [7][16], so this factor is not be included my theoretical model.

Second, several researchers discuss demographics characteristics affect mobile commerce users acceptance [16]. So the user demographics, such as gender, age, profession, income, and marital status, are in this theoretical model.

Third, information system is not cultural neutral. The development of mobile commerce will be mostly affected by the typical social, economic, and cultural backgrounds [16]. Hua Dai and Prashant Palvia have conducted a cross-cultural analysis of mobile commerce adoption. They found significant differences among the factors and their impact on consumers' intentions to use mobile commerce.

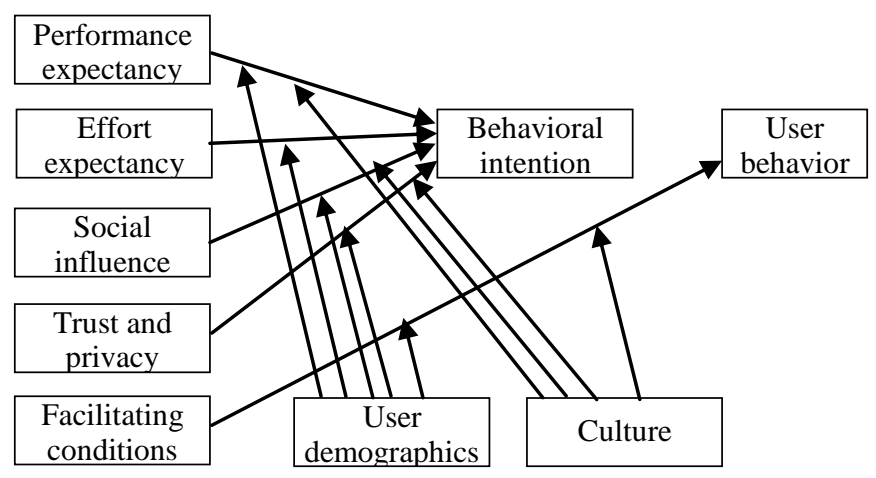

Figure 2. Proposed research model

Fig. 2 above gives a synopsis of the theoretical model.

\section{CONCLUSION AND FUTURE WORK}

In this paper, based on systematic literature review and incorporation the unique characteristic of mobile commerce, the theoretical model was developed. Meanwhile, the four phases study combing qualitative and quantitative methods was proposed.

As mobile commerce is a relatively new research area in china, the theoretical model developed in this paper may be have some practical issues. The future study is to conduct the next study phases to perfect the model. The qualitative analysis, questionnaires survey and focus group interview, help further understanding the acceptance and use mobile commerce behaviors. In the final phase, the empirical survey study will be conducted to test the theoretical model. By validation of the theoretical model with empirical data, important differences and commonalities in users' intention to use mobile commerce will be identified. They will help to better explain and predict user resistance, acceptance and actual use.

\section{REFERENCES}

[1] Ruidong Zhang, Tom Hilton. "The characteristics and technical foundations of mobile commerce". Issues in Information Systems, vol. 13, no.2, pp. 394-396, 2012.

[2] Sadeh N M. M-Commerce: technologies, services and business models . New York: Wiley \& Sons, 2002.

[3] Leigh Williamson. "A mobile application development primer". IBM Software Thought Leadership White Paper, 2012.

[4] CNNIC. "The research report on mobile phone netizens behavior in china ". http://www.cnnic.net.cn, 2011.

[5] Ge Wei, Zhao Xinyan, Ma Yue. "Literature review on consumer adoption behavior of mobile commerce services". 2011 International Conference on E-Business and E-Government (ICEE), pp.1-5, 2011.

[6] Venkatesh V, Morris M G, Davis GB Davis, FD Davis. "User 15acceptance of information technology: towards a unified view ". MIS Quarterly, vol.27, no.3, pp.425-478, 2003.

[7] Bedford,Deward Wayne. "Empirical investigation of the acceptance and intended use of mobile commerce:location,personal privacy and trust". Mississippi State University, 2005,

[8] Jarvenpaa, S. L., Lang, K. R. "Managing the paradoxes of mobile technology". Information Systems Management, vol.22, no.4, pp.7-23, 2005.

[9] Siau K, Shen Z. "Building customer trust in mobile commerce". Communications of the ACM, vol.46, no.4, pp.91-94, 2003.

[10] Dayal, S., Landesberg, H., Zeisser, M. "How to build trust online"]. Marketing Management, vol.8, no.3, pp.64-69, 1999. 
[11] Gefen D. "Customer loyalty in E-Commerce". Journal of the Association of Information Systems, no.3, pp.27-51, 2002.

[12] Niina Mallat. "Exploring consumer adoption of mobile payments - a qualitative study “. http://sprouts.aisnet.org/6-44, 2006.

[13] Palen L., Salzman M., Youngs, E. "Going wireless: behavior \& practice of new mobile phone users ". Proceedings of 2000 ACM Conference On Computer Supported Cooperative Work, ACM Press New York, NY, Philadelphia, Pennsylvania, USA, pp.201-210, 2000.

[14] Sheng, H., Nah, F. F., Siau, K. "An experimental study on ubiquitous commerce adoption: Impact of personalization and privacy concerns". Journal of the Association for Information Systems, vol.9, no.6, pp.344376, 2008.

[15] Spiekermann, S., Grossklags, J., Berendt, B. "E-privacy in 2nd generation E-commerce: privacy preferences versus actual behavior" . In the Proceedings of the 3rd ACM conference on Electronic, 2001.

[16] MIN Qingfei, JI Shaobo, QU Gang. "Mobile commerce user acceptance study in China: a revised UTAUT Model". TSINGHUA SCIENCE AND TECHNOLOGY, vol.13, no.3, pp.257-264, 2008.

[17] Venkatesh V. "Determinants of perceived ease of use: integrating control, intrisic motivation, and emotion into the Technology Acceptance Model". Information Systems Research, vol.11, no.4, pp.342-365, 2000.

[18] Heijden V D. "User acceptance of hedonic information systems". MIS Quarterly, vol.28, no.4, pp.695-704, 2004.

[19] Bisdikian C., Christensen J., John Davis, Maria R. Ebling, Guerney Hunt, William Jerome, et al. "Enabling location-based application". Proceeding of the first international workshop on mobile commerce, ACM Press New York, NY, USA, Rome, Italy, pp.38-42, 2001.
[20] Tarasewich P., Nickerson R.C., Warkentin M. "Issues in Mobile ECommerce". Communications of the Association for Information Systems, no.8, pp.41-64, 2002.

[21] Clark D. "Speech recognition: the wireless interface revolution" . Computer, vol.34, no.3, pp.16-18, 2001.

[22] Ozen B., Kilic O., Altinel M., Dogac A. "Highly personalized information delivery to mobile clients". Proceeding of the Second ACM International Workshop on Data Engineering for Wireless and Mobile Access, ACM Press New York, NY, USA, Santa Barbara, California, United States,pp.35-42, 2001.

[23] I-ping Chiang, Yi-Shiang Liao. "Exploring the key success factors of mobile commerce in Taiwan". 26th International Conference on Advanced Information Networking and Applications Workshops, pp. 369-374, 2012.

[24] Ruebeck C., Stafford S., Tynan N., William Alpert, Gwendolyn Ball, and Bridget Butkevich. "Network externalities and standardization: a classroom demonstration". Southern Economic Journal, vol.69, no.4, pp.1000-1008, 2003.

[25] Junglas I. A., Watson, R. T. "U-commerce: a conceptual extension of ecommerce and mobile commerce". In the Proceedings of the twentyfourth international conference on information systems, pp.667-677, 2003.

[26] Zhou T., Lu Y., Wang B. "Integrating TTF and UTAUT to explain mobile banking user adoption". Computers in Human Behavior, vol.26, no.4, pp.760-767, 2010.

[27] Anindya G., Avi Goldfarb, Sang Pil Han. "How is the mobile internet different? Search costs and local activities". Thirty Second International Conference on Information Systems, pp.1-18, 2011. 